2. Matthaei M, Hribek A, Clahsen $T$, Bachmann B, Cursiefen C, Jun AS. Fuchs Endothelial Corneal Dystrophy: Clinical, Genetic, Pathophysiologic, and Therapeutic Aspects. Annu Rev Vis Sci. Sep 15 2019;5:151-175. doi:10.1146/annurev-vision-091718-014852

3. Greene JB, Mian SI. Cataract surgery in patients with corneal disease. Curr Opin Ophthalmol. Jan 2013;24(1):9-14 doi:10.1097/ICU.0b013e32835aeec4

4. Malandain E, Gueudry J, Boutillier G, Muraine M. [Outcomes of cataract surgery in patients with Fuchs endothelial corneal dystrophy]. J Fr Ophtalmol. Oct 2021;44(8):1180-1189. Chirurgie de cataracte seule chez le patient porteur d'une dystrophie endotheliale de Fuchs. doi:10.1016/j.jfo.2020.09.033

5. Elhalis $\mathbf{H}$, Azizi B, Jurkunas UV. Fuchs endothelial corneal dystrophy. Ocul Surf. Oct 2010; 8 (4):173-84. doi:10.1016/s1542-0124(12)70232-x

6. Lề Xuân Cung. Nhân xét đăc điểm lâm sàng và bệnh lý giải phâuu của bệnh loạn dưỡng giác mạc di truyền - gia đình. Luận văn tốt nghiêpp bác sĩ nội trú bệnh viện. Trường đại hoc Y Hà Nội; 1999.

7. Kopplin Lj, Przepyszny K, Schmotzer B, et al. Relationship of Fuchs endothelial corneal dystrophy severity to central corneal thickness. Arch Ophthalmol. Apr 2012;130(4):433-9. doi:10.1001/archopthalmol.2011.1626 10.1001/archophthalmol.2011.1626

8. Pateras E, Koufala C. Comparison between OrbscanIIz, Pentacam, Ultrasound Pachymetry (Tomey SP-100) at Different Stages of Keratoconus. Ophthalmology Research An International Journal. 07/16 2020;13:7-33. doi:10.9734/OR/2020/v13i230163

\title{
GIÁ TRI CHẨN ĐOÁN CỦA PHIM CộNG HƯỞNG TỪ ĐỐI VỚI TỔN THƯƠNG SỤN KHỚP GỐI DO THOÁI HOÁ
}

\section{TÓM TẮT}

Mục tiêu: phân tích giá trị chẩn của phim công hưởng từ đối với tổn thương sụn khớp gối do thoái hoá, dưa trên tiêu chuẩn vàng là nội soi khớp. Pháp nghiên cứu: nghiên cứu trển 76 bệnh nhân được chẩn đoán thoái hoá khớp gối dưa trên Xquang thường quy, theo tiêu chuẩn của Kell-gren-Lawrence, được phâuu thuật nội soi khớp gối. Tât cả đều đước chụp cộng hưởng từ (MRI) trước mổ. Mức độ tổn thương sụn khớp trên MRI được phân loại theo Vallotton. Tổn thương trong mổ nội soi khớp đước phân độ theo Outer Bridge. Kết quả: Độ nhạy, độ đặc hiệu, giá trị dự đoán dương tính, giá trị dự đoán âm tính và độ chính xác lần lượt là $69,7 \%, 85,8 \%, 80,9 \%$, $79,7 \%$ và $82,6 \%$. Kết luân: Hình ảnh $\mathrm{CHT}$ cho thấy độ đặc hiệu, các giá trị chẩn đoán dương tính và âm tính, và độ chính xác cao hơn so với chụp $X$ quang (theo các số liệu nghiên cứu trước đó)

Tư khoá: Thoái hoá khớp gối, Cộng hưởng từ, độ đặc hiệu, độ chính xác.

\section{SUMMARY \\ DIAGNOSTIC VALUE OF MAGNETIC RESONANCE \\ IMAGES IN PATIENTS WITH ARTHROSCOPIC OSTEOARTHRITIS OF THE KNEE}

Objectives: The aim of this study is to analyze the diagnostic value of magnetic resonance images (MRI) in osteoarthritic knees when using arthroscopic

${ }^{1}$ Đai Hoc Y Hà Nôi

${ }^{2}$ Bệnh viện HN Việt Đức

Chiu trách nhiêm chính: Dương Đình Toàn

Email: duongdinhtoan@hmu.edu.com

Ngày nhận bài: 8.9.2021

Ngày phản biện khoa học: 26.10.2021

Ngày duyệt bài: 10.11.2021

\section{Dương Đình Toàn ${ }^{1,2}$}

ndings as the "gold standard" to compare with. Method: A total of 76 patients were studied because of chronic pain in 1 of their knees. Radiographs were classified according to Kell- gren-Lawrence scale. Magnetic resonance images were classified according to Vallotton, and arthroscopic ndings according to Outer- bridge criteria. Results: Sensitivity, specificity, positive predictive value, negative predictive value, and accuracy were, respectively $69,7 \%, 85,8 \%$, $80,9 \%, 79,7 \%$, and $82,6 \%$ for MRI. Conclusion: Magnetic resonance images presented higher specificity, positive and negative predictive values, and accuracy than weight-bearing radiographs for knee osteoarthritis (according to other research)

Key words: radiography, osteoarthriti, bone spurs

\section{I. ĐĂT VẤN ĐỀ}

Cộng hưởng từ (MRI) là một phương tiên chẩn đoán có giá trị đối với bệnh thoái hóa khớp gối (THKG). Mức độ tổn thương thoái hóa sụn có thể được đo bằng hê thống phân loai Vallotton trên MRI [1]. Theo các nghiên cứu khác, độ nhạy của MRI chỉ đat $60 \%$ đối với những tổn thương sụn mâm chầy, đặc biệt ở mức độ thoái hoá nhẹ trong, trong khi độ đặc hiệu cao hơn 90\% [2]. Đối với những trường hợp thoái hoá nhe, độ nhay có thể từ $0 \%$ đến $86 \%$, đô đặc hiệu là $48 \%$ đến $95 \%$. Trong khi thoái hoá nặng, độ nhay có thể lên đến $98 \%$ đến $100 \%$ [3]. MRI cũng được coi là một công cư tốt hơn để đo lường sự tiến triển của thoái hoá. Giá tri chẩn đoán của MRI đối với chẩn đoán thoái hóa khớp gối còn phụ thuộc vào sức mạnh từ tính, nghĩa là MRI 3.0T kết quả chẩn đoán sẽ tốt hơn so với 
MRI 1,5T [4].

Một nghiên cứu về mối liên quan giữa sự tiến triển của hẹp khe khớp trên hình ảnh $X$ quang và mất sụn trên $M R I$, đã kết luận rằng $X$ quang không phải là một phương tiên có độ nhạy cao, và nếu chỉ sử dụng một mình $X$ quang để chẩn đoán thoái hoá khớp gối thì sẽ bỏ sót một tỷ lệ đáng kể trong chẩn đoán tình trạng mất sụn. Tuy nhiên, kết hợp cả Xquang và MRI có thể có thể nâng cao giá trị chẩn đoán [5]. Tính hữu ích của sự kết hợp của hai công cụ để chẩn đoán thoái hóa khớp gối đã được mô tả trong một số nghiên cứu, nhưng độ chính xác của riêng MRI ít được đề cập.

\section{II. ĐỐI TƯỚNG VÀ PHƯƠNG PHÁP NGHIÊN CỨU}

2.1. Thời gian nghiên cứu: $10 / 2015-4 / 2018$.

2.2. Địa điểm nghiên cứu: Viện chấn thương chỉnh hình Bệnh viện Hữu Nghị Việt Đức

2.3. Đối tượng và phương pháp nghiên cứu:

Đôi tượng nghiên cứu. Nghiên cứu được tiến hành trên một nhóm bệnh nhân THKG, được phẫu thuật nội soi làm sạch. Dấu hiệu tổn thương sụn khớp trên MRI trước mổ được so sánh với hình ảnh tổn thương trong mổ

\section{Tiêu chí lựa chọn}

- Lâm sàng: Bệnh nhân đau mãn tính khớp gối trên 6 tháng, làm hạn chế đi lại ở các mức độ khác nhau. $X$ quang: có hình ảnh của thoái hóa khớp gối

- Bệnh nhân không có các bệnh lý phối hợp

- Bệnh nhân đồng ý tham gia nghiên cứu

Tiêu chí loại trừ

- Viêm khớp nhiễm khuẩn hoặc viêm khớp do bệnh tự miễn

- Viêm khớp go gút

- Nhiễm trùng cấp tính và / hoặc mãn tính cục bộ ở khớp gối và / hoặc

di chứng của nhiễm trùng khớp trước đó

- Đã từng phẫu thuật ở khớp gối

2.4. Thiết kế nghiên cứu: Nghiên cứu mô tả cắt ngang.

\subsection{Phương pháp nghiên cứu}

Chụp MRI: tất cả khớp gối đều được chụp bằng chụp MRI 1,5T của hãng Siemems trước mổ. Kết quả tổn thương sụn khớp trên MRI được Bác sỹ chuyên khoa chẩn đoán hình ảnh phẩn tích. Mức độ tổn thương sụn được đánh giá theo tiêu chuẩn Vallontton, theo đó độ 0 (sụn bình thường), độ I (bề mặt sụn còn nguyển vẹn, nhưng có dấu hiệu tăng tín hiệu trên T2), độ II (bề mặt sụn bất thường hoặc giảm bề dày của sụn < 50\%), độ III (bề mặt sụn tổn thương, giảm bề dày > 50\%) và độ IV (tôn thương hoàn toàn bề dày của sụn)

Nội soi khớp gối: trong mổ đánh giá tổn thương sụn tại các vị trí lồi cầu đùi, mâm chầy và khớp chè đùi. Mức độ tổn thương được đánh giá theo Outer Bridge, theo đó độ 0 (sụn khốp bình thường), độ I (bề mặt sụn còn nguyên vẹn nhưng mất tính đàn hồi), độ II (bề mặt sụn tổn thương $<50 \%$ bề dày của sụn), độ III (bề mặt sụn tổn thương $>50 \%$ bề dày) và độ IV (mất sụn hoàn toàn, lộ xương dưới sụn)

\section{KẾT QUẢ NGHIÊN CỨU}

\section{1. Đặc điểm đối tượng nghiên cứu}

Bảng 3.1. Phân bố bệnh theo tuổi, giới $(n=76)$

\begin{tabular}{|c|c|c|c|}
\hline \multicolumn{1}{|c|}{ Đặc điếm đối tượng } & $\mathbf{n}$ & $\mathbf{\%}$ \\
\hline \multirow{3}{*}{ Tuổi } & $40-49$ & 8 & $10,5 \%$ \\
\cline { 2 - 4 } & $50-59$ & 47 & $61,9 \%$ \\
\cline { 2 - 4 } & $60-70$ & 21 & 27,6 \\
\hline \multirow{2}{*}{ Giới } & Nam & 24 & 31,5 \\
\cline { 2 - 4 } & Nữ & 52 & 68,5 \\
\hline
\end{tabular}

Nhận xét: Độ tuối trung bình là 54,82 (4669), nhóm tuổi gặp nhiều nhất là $50-59$, chiếm $63 \%$. Nữ nhiều hớn nam, với tỷ lệ là $2: 1$.

Bảng 3.2. Phân bố bệnh nhân theo chi số BMI $(n=76)$

\begin{tabular}{|c|c|c|c|}
\hline Phân loại & BMI $\mathbf{( k g / m 2 )}$ & $\mathbf{n}$ & $\mathbf{\%}$ \\
\hline Thiếu cân & $<18.5$ & 0 & 0 \\
\hline Bình thường & $18.5-22.9$ & 15 & 19,7 \\
\hline Thừa cân & $23-24.9$ & 34 & 44,7 \\
\hline Béo phì độ I & $25-29.9$ & 25 & 32,9 \\
\hline Béo phì độ II & $\geq 30$ & 2 & 2,7 \\
\hline
\end{tabular}

Nhânn xét: Từ bảng 3.2 cho thấy, nhóm thừa cân và béo phì chiếm $77,6 \%$, trong đó chủ yễu là thừa cân và béo phì độ I.

3.2. Đặc điểm tổn thương trên phim XQ

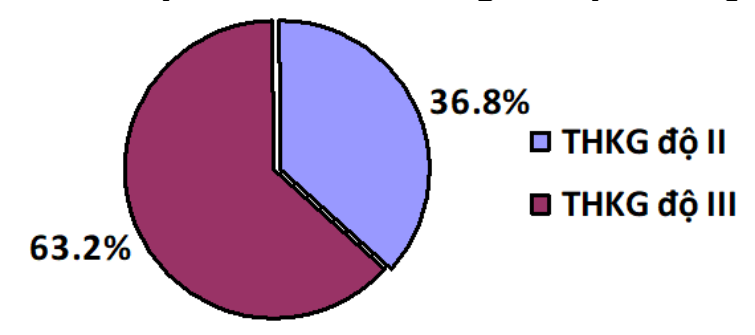

\section{Biểu đồ 3.1. Mức độ THKG trên XQ theo Kell-gren-Lawrence}

Nhận xét: trong nhóm nghiên cứu, phần lớn bệnh nhân là THKG độ III, chiếm tỷ lệ 63,2\%. Trong khi đó, THKGđộ II chỉ chiếm 36,8\%.

3.3. Mức độ THKG trên MRI theo Wallotton $(n=70)$ 


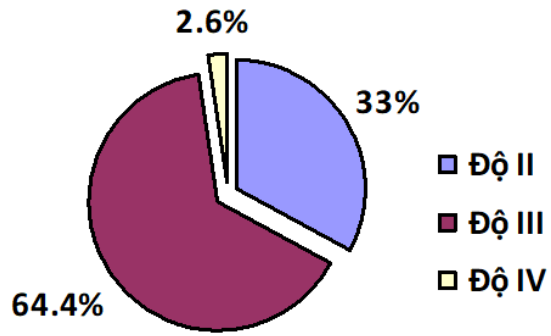

Biểu đồ 3.2. Mức độ THKG trên MRI theo Wallotton

Nhận xét: Tổn thương trên phim MRI, ngoài thoái hoá độ II $(33 \%)$, độ III $(64,4 \%)$ còn phát có 2 trường hợp thoái hoá độ IV, chiếm 2,6\%

3.4. Mức độ THKG trong mổ $(n=70)$

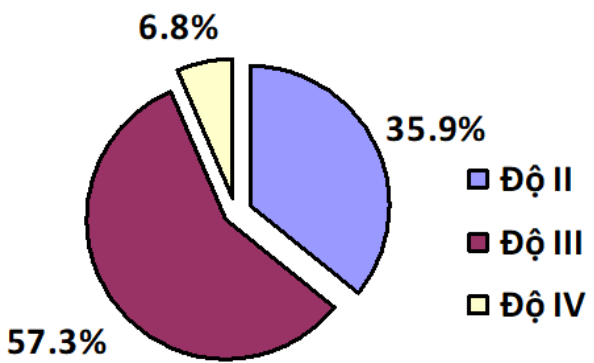

Biểu đồ 3.3. Mức độ THKG trong mổ theo OuterBridge

Nhận xét: Tổn thương trong mổ, ngoài thoái hoá độ II $(35,9 \%)$, độ III $(57,3 \%)$ còn phát có 5 trường hợp thoái hoá độ IV, chiếm 6,8\%,

3.5. Giá trị chẩn đoán của MRI trong chẩn đoán THKH

Bảng 3.3. Đô nhạy, độ đặc hiệu, giá trị dự đoán dương tính/âm tính và độ chính xác của MRI đôi với các múrc độ THKG

\begin{tabular}{|c|c|c|c|c|c|}
\hline Độ & $\begin{array}{c}\text { Độ nhạy } \\
(\mathbf{\%})\end{array}$ & $\begin{array}{c}\text { Độ đặc hiệu } \\
\mathbf{( \% )}\end{array}$ & $\begin{array}{c}\text { Giá trị dự đoán } \\
\mathbf{+}(\mathbf{\%})\end{array}$ & $\begin{array}{c}\text { Giá trị dự } \\
\text { đoán }\end{array}$ & $\begin{array}{c}\text { Độ chính xác } \\
(\mathbf{\%})\end{array}$ \\
\hline II & 55,3 & 85,8 & 35,6 & 92,7 & 84,4 \\
\hline III & 51,0 & 95,2 & 72,7 & 86,2 & 87,5 \\
\hline IV & 47,2 & 92,7 & 63,2 & 77,9 & 90.1 \\
\hline
\end{tabular}

Nhân xét: Mức độ thoái khớp càng nặng thì độ đặc hiệu và độ chính xác của MRI có xu hướng càng tằng

Bảng 3.4 Độ nhạy, độ đặc hiệu, giá trị dự đoán dương tính/âm tính và độ chính xác của MRI đối với THKG

\begin{tabular}{|c|c|c|c|c|c|}
\hline Độ & $\begin{array}{c}\text { Độ nhạy } \\
(\%)\end{array}$ & $\begin{array}{c}\text { Độ đặc hiệu } \\
(\%)\end{array}$ & $\begin{array}{c}\text { Giá trị dự đoán } \\
+(\%)\end{array}$ & $\begin{array}{l}\text { Giá trị dứ } \\
\text { đoán - }(\%)\end{array}$ & $\begin{array}{c}\text { Độ chính xác } \\
(\%)\end{array}$ \\
\hline MRI & 69,7 & 85,8 & 80,9 & 79,7 & 82,6 \\
\hline
\end{tabular}

Nhận xét: Độ nhạy, độ đặc hiệu và giá trị dự đoán (+) của MRI khá cao, đều trên $80 \%$, trong khi đó độ nhạy của MRI chỉ ở mức 69,7\%

\section{BÀN LUÂNN}

Nghiên cứu của Galea và Cs khi so sánh với kết quả nội soi khớp, độ nhay của MRI trong chẩn đoán thoái hóa khớp gối thay đổi từ $58 \%$ đến $97 \%$, trong khi độ đăcc hiệu được tính toán nằm trong khoảng từ $85 \%$ đên $100 \%[6]$. Các số liệu của chúng tôi cũng tương tự (Bảng 3.4). Theo Nghiên cứu của Von và $\mathrm{Cs}$, độ chính xác được ước tính là $47 \%$ đến $69 \%$ [2], trong khi chúng tôi thu được giá trị là $82,6 \%$. Theo dữ liệu của chúng tôi, một số bệnh nhân của Outerbridge độ IV đã được chẩn đoán là độ III bằng MRI, như nó cũng đã được mô tả trước đây. Các tác giả khác đưa ra số liệu thấp về độ nhạy (từ $20 \%$ đến $94 \%$ đối với độ II-III ) và cao hơn (từ 77\% đến 100\%) ở độ IV nhưng được cải thiện khi sử dụng máy MRI 3.0T (thay vì $1,5-\mathrm{T}$ được sử dụng trong nghiên cứu của chúng tôi). Tuy nhiên, chi phí kinh tế của chụp MRI 3.0T gấp hơn gần 2 lần so với chụp MRI 1.5T, điều này cũng cần được cân nhắc khi lựa chọn phương tiện chẩn đoán.

Một số nghiên cứu đã phân tích giá trị chẩn đoán MRI và đề xuất có thể lấy MRI làm "tiêu chuẩn vàng" để chẩn đoán THKG mà không cần nội soi khớp. Tuy nhiên trên thực tế, quả thu được ít có giá trị hơn về mặt thống kê và lâm sàng so với kết quả thu được khi so sánh với hình ảnh nội soi khớp trực tiếp, vì các nghiên cứu liên quan chỉ ra rằng nội soi khớp là kỹ thuật phù hợp nhất để đánh giá thoái hóa mô sụn trong bệnh lý thoái hoá khớp.

\section{KẾT LUẬN}

Chụp cộng hưởng từ cho thấy độ đặc hiệu, giá trị dự đoán dương và âm tính, cững như độ chính xác cao hơn so với chụp $X$ quang khớp gối trong chẩn đoán thoái hóa khớp gối. Cả hai công cụ chẩn đoán đều cho kết quả tốt hơn khi mức độ thoái hoá của khớp tăng lên. Sự kết hợp của Xquang và MRI không làm tăng độ chính xác trong chẩn đoán thoái hóa khớp gối, so với chì MRI. Trong thực tế lâm sàng, có thể nói khi đã 
có kết quả chụp $X$ quang, nếu có thêm MRI sẽ rất hữu ích, đặc biệt là đối vớ thoái hóa khớp gối mức độ vừa phải trước khi phẫu thuật nội soi khớp. Hơn nữa, nếu MRI đã được thực hiện, có thể không cần thiết chụp $X$ quang trong các trường hợp thoái hóa khớp gối mức độ nhẹ.

\section{TÀI LIÊU THAM KHẢO}

1. Vallotton JA, Meuli RA, Leyvraz PF, Landry M. Comparison between magnetic resonance imaging and arthroscopy in the diagnosis of patellar cartilage lesions: a prospective study. Knee Surg Sports Traumatol Arthrosc. 1995;3:157-162.

2. Von Engelhardt LV, Lahner M, Klussmann A, et al. Arthroscopy vs. MRI for a detailed assessment of cartilage disease in osteoarthritis: diagnostic value of MRI in clinical practice. BMC Musculoskelet Disord. 2010;11:75.
3. Quatman CE, Hettrich CM, Schmitt LC, Spindler KP. e clinical utility and diagnostic performance of magnetic resonance imaging for identi cation of early and advanced knee osteoarthritis: a systematic review. Am J Sports Med. 2011;39:1557-1568.

4. Kijowski $R$, Blankenbaker DG, Davis KW, Shinki K, Kaplan LD, De Smet AA. Comparison of 1.5- and 3.0-T MR imaging for evaluating the articular cartilage of the knee joint. Radiology. 2009;250:839-848.

5. Agnesi F, Amrami KK, Frigo CA, Kaufman KR. Comparison of cartilage thick- ness with radiologic grade of knee osteoarthritis. Skeletal Radiol. 2008;37:639-643.

6. Galea A, Giu re B, Dimmick S, Coolican M, Parker D. e accuracy of mag- netic resonance imaging scanning and its in uence on management decisions in knee surgery. Arthroscopy. 2009;25:473-480.

\section{KẾT QUẢ CHĂM SÓC NGƯờI BÊ̂NH SAU PHẪU THUÂT UNG THƯ DẠ DÀY TẠI BÊ̂NH VIÊ̂N K NĂM 2020 - 2021 VÀ MộT Số YẾU Tố LIÊN QUAN}

\section{TÓM TẮT}

Phương pháp chủ yếu trong điều trị ung thư da dày là phâuu thuật bao gồm những trường hợp bệnh giai đoạn sớm hay cả giai đoạn muộn. Sự theo dõi chăm sóc người bệnh của cán bộ điều dưỡng đóng vai trò rất quan trọng giúp cho người bệnh sau phẫu thuật ung thư da dày đat kết quả tốt trong điều tri. Mục tiêu: Mô tả đặc điểm lâm sàng, phân tích kểt quả chăm sóc người bênh sau phẩu thuật ung thư dạ dày và tìm hiểu một số yếu tố liên quan. Đối tượng và phương pháp: Thiết kế nghiên cứu mô tả cắt ngang trên 148 người bệnh ung thư dạ dày sau phẫu thuât cắt đoan da dày, thu thâp thông tin về chăm sóc ngừ̛̛̛i bệnh theo quy trình điều dưỡng tại phòng hậu phẫu và các phòng bênh cho đến khi người bênh ra viện. Kết quả: Kểt quả chăm sóc người bệnh tốt là $83,4 \%$. Các yếu tố liên quan đến kết quả chắm sóc tốt gồm: Nhóm tuổi, thói quan cá nhân, bệnh lý kèm theo, giai đoạn bệnh, phương pháp phẩu thuật và thời điểm ăn đường miệng.

Từ khóa: Ung thư dạ dày, phẫu thuật, chăm sóc.

\section{SUMMARY \\ RESULTS OF CARE OF PATIENTS AFTER SURGERY STOMACH CANCER AT K HOSPITAL IN 2020 - 2021 AND SOME FACTORS RELATED}

*Bệnh viên $K$

Chịu trách nhiệm chính: Trân Đắc Thành

Email: thanhbvk@gmail.com

Ngày nhân bài: 10.9.2021

Ngày phản biên khoa hoc: 28.10.2021

Ngày duyệt bài: 12.11.2021

\section{Trần Đắc Thành*}

The main method in the treatment of stomach cancer is surgery, including cases of early or late stage disease. The follow-up care of patients by nursing staff plays a very important role in helping patients after gastric cancer surgery achieve good results in treatment. Objectives: Description of the clinical features, analyze the outcome of patient care after gastric cancer surgery and find out some related factors. Subjects and methods: Design a crosssectional descriptive study on 148 gastric cancer patients after gastric bypass surgery, collect information on patient care according to the nursing process in the postoperative room and other medical staff. patient care until the patient is discharged from the hospital. Results: Good patient care outcome was $83.4 \%$. Factors related to good care outcomes include: Age group, personal habits, comorbidities, disease stage, surgical method and time of oral intake.

Keywword: Stomach cancer, surgery, take care

\section{I. ĐẶT VẤN ĐỀ}

Theo thống kê của Cớ quan nghiên cứu ung thư quốc tế (IARC), năm 2020 ung thư dạ dày có tỷ lệ mắc phổ biến thứ năm trên toàn thể giới với $5,6 \%$ tương đương với 1,089 triệu người mắc mới, tỷ lệ tử vong đứng thứ tư ở cả hai giới. Cũng theo báo cáo trên thì tại Việt Nam năm 2020 ước tính có 17.906 ca mắc mới đứng thứ tư và chiếm 9,8\% trong các loại ung thư [1].

Phẫu thuật là phương pháp chủ yếu điều trị ung thư dạ dày. Ớ giai đoạn sớm, ung thư còn giới hạn tại chỗ và vùng, phẫu thuật được lựa chọn là phương pháp điêuu trị triệt căn. Những 